\title{
Prediction of Hydroxyl Substitution Site(s) of Phenol, Monochlorophenols and 4-Chloronitrobenzene by Atomic Charge Distribution Calculations
}

\author{
Byung-Dae Lee ${ }^{\dagger}$ and Min-Joo Lee* \\ Department of Chemistry, Changwon National Chiversitv, Changwon, Gyungnam 641-773, Korea \\ E-mail: mjleeâchangwion ackr \\ Division of Health, Uiduk Liniversity, Gyungin, Gungbuk 780-713, Korea \\ Received Mav 20, 2008, Accepted August 9, 2008
}

\begin{abstract}
The predictions of the radical reaction sites for phenol, 2-,3- and 4-chlorophenols (CPs) and 4-chloronitrobenzene $(\mathrm{CNB})$ were studied by atomic charge distribution calculations. The atomic charge distributions on each atom of these molecules were obtained using the CHelpG and MK (Merz-Kollman/Singh) methods with the optimized structural parameters determined by DFT calculation at the level of BLYP/6-311+G(d,p). By comparing the experimentally obtained hydroxyl addition site(s) and the calculated atomic charges on carbon atoms of phenol and CPs, we found that hydroxyl substitution by oxidation reaction mainly occured to the carbon(s) with high atomic charges. With these results, we were easily able to predict the position(s) of the OH reaction site(s) of phenol, CPs and $\mathrm{C} N \mathrm{NB}$ through atonic charge distribution calculations.
\end{abstract}

Key Wonds: Atomic charge distribution. CHelpG. MK. Hydroxỵl radical reaction

\section{Introduction}

Chlorophenols (CPs) have widely been used as pesticides. germicides. and wood preservatives and have largely' been used in the manufacturing processes of products using leather, fiber. and pulp paper. ${ }^{1}$ CPs contain toxic elements and there have recently been reported several cases of CP contaminating soil and underground water. ${ }^{2}$ Thus, a variety of treatment methods. such as reductive dechlorination. ${ }^{3}$ ultraviolet (UV) imadiation. ${ }^{4,5}$ ozone oxidation. ${ }^{6}$ and Fenton oxidation, have been studied in order to dispose of CPs contamination.

The research that has been most actively carried out is the reductive dechlorination of $\mathrm{CPs}^{3}$ using anaerobic microorganism. However this method takes a long time for the CPs to decompose. and is not applicable in case of high concentration contamination. On the other hand the UV treatment ${ }^{4.5}$ refers to a method that dechlorinates CPs with a UV light and has the ability to dispose of high concentrated CPs at a comparatively low price, compared to other treatments. However. this method has limitations. When it is used in real circumstances where suspended solids are present in the water. the UV light irradiates poorly and the treatment efficiency is drastically decreased. In the meantime there have been several studies being performed on the oxidation process using catalysts produced by' ozone oxidation ${ }^{6}$ and Fenton oxidation. ${ }^{7}$ These methods pose as an effective treatment technology to complement the weaknesses of the UV method. This treatment removes chlorines by reacting $\mathrm{CPs}$ with $\cdot \mathrm{OHs}$ generated by ozone or Fenton reaction. These ozone and Fenton oxidation methods have the merits of short processing time and the possibility of application even in a turbid target solution.

Thus, to remove the hamnful chlorinated organic compounds efficiently including $\mathrm{CPs}$ which are the by-products of industrial processes, a variety of experimenta $1^{3.0}$ and theoretical ${ }^{8.16}$ studies are being carried out. To evaluate the photo degradation characteristics of chlorinated organic compounds, several studies using the density functional theory (DFT) method have been reported. ${ }^{8-11}$ However. studies that analyze the radical reaction of chlorinated organic compounds including phenol by using the DFT method have not been reported yet. Until recently. there have merely been studies predicting the reaction of formaldelyde with alkaline phenol among phenol conpounds based on the calculation of the atonic charges. ${ }^{1:-14}$ Thus, to understand the $\mathrm{OH}$ substitution reaction of phenols, CPs and CNB at the molecular level, it is important to predict what products are made in radical reaction by Fenton or ozone. A deep comprehension of the $\cdot \mathrm{OH}$ reaction mechanism of these hannful chlorinated organic compounds is also important. In addition. establishing such an accurate and easy technique to predict the products generated after the radical reaction helps a highly reliable prediction of the decomposition possibility by the radical reaction. Also, the reacting site(s) and products made during the decomposition of many kinds of chlorinated organic compounds are also easily and rapidly predicted. The method mentioned above is expected to make a great contribution to induce reliable optimal factors in the design of means for decomposing and disposing pollutants such as radicals. Therefore, we investigated the position(s) of the radical reaction site(s) on phenol. CPs and CNB using atonic charge distribution calculations.

\section{Calculation}

In this study. to predict the decomposition products of phenol, $\mathrm{CPs}$ and $\mathrm{CNB}$ using $\cdot \mathrm{OH}$ radical, the plane figures of all the molecules in this study were drawn using the ChemDraw program. ${ }^{17}$ In addition, the three-dimensional features of these figures were confirmed with the Chem3D program using the CS Chem3D program package. ${ }^{17}$ With the Chem3D program, the Gaussian input files were created to run the Gaussian-98 program. ${ }^{18}$

We also carried out density functional theory calculations 
with Becke's exchange functional (BLYP) ${ }^{19.2(1}$ to obtain the optimized geometrical parameters of the molecules at the level of BLYP/6-311++G(d.p). The $\cdot \mathrm{OH}$ attacks the atom on benzene ring of each molecule which has strongly electrophile. Therefore the atomic charge distributions were calculated for the carbon of the benzene ring using the $\mathrm{CHelpG}^{21}$ and $\mathrm{MK}$ (Merz-Kollman/ Singh) ${ }^{2+23}$ methods with these optimized molecular structures

\section{Results and Discussion}

Hydroxyl group substitution by oxidation. Under the ozone oxidation reaction ${ }^{2-}$ the $\mathrm{OH}$ is generated by the underwater ozone decomposition. However, in an oxidation reaction with the presence of a catalyst such as the Fenton reaction. the radical is produced from hydrogen peroxide $\left(\mathrm{H}_{2} \mathrm{O}_{2}\right)$ in the coexistence of a catalyst ( $\mathrm{Fe}^{-2}$ and etc.). The $\mathrm{OH}$ generated in this way attacks the carbon with a benzene ring. creating a reactive product in the form of a hydroxyl compound or making a product with a benzene ring open. These reactive products are attacked again by $\mathrm{OH}$ or other kinds of radicals and create the final products that have been further oxidated. ${ }^{-6-28}$

Literary research on radical decomposition. Table 1 shows the physical and chemical characteristics of phenol. CPs. and CNB, which are target substances in this study. As seen in Table 1, all the target substances show high relative boiling points. so it seems that the volatilization possibility of these target substances in the ozone and Fenton oxidation test under the open system. which has been reported in the literature, $^{6.7 .15-16,36.28}$ is low. In addition, as the octanol/water partition coefficients of CPs and CNB reach high peaks. they have been the focus of important research subjects because

Table 1. Chemical properties of considered CPs. ${ }^{2020 . a}$

\begin{tabular}{|c|c|c|c|c|}
\hline Structure & Name & $\mathrm{w}_{\mathrm{m}}$ & b.p. $f^{N} \mathrm{C}$ & $\log K_{\mathrm{su}}$ \\
\hline & phenol & 94.11 & 182 & 1.46 \\
\hline & 2-chlorophenol & 128.55 & 176 & 2.15 \\
\hline & 3-chlorophenol & 128.55 & 214 & 2.52 \\
\hline & 4-chlorophenol & 128.55 & 220 & 2.39 \\
\hline & 4 -chloronitrobenzene & 157.55 & 242 & 2.39 \\
\hline
\end{tabular}

"Abbreviations used: " we molecular weight; b.p., boiling point: $K_{0 w}$, octanol-water partition coefficient. those substances may end up highly concentrated in the biological organisms through the food chain.

Table 2 shows the oxidation products reported in the experiments using target substances. As shown in Table 2. all the oxidation products reported in the literature ${ }^{26-2 \times 31-32}$ indicate the conpound structure in which a hydroxyl group $(-\mathrm{OH})$ has been substituted from the original target substance.

Atomic charge calculation. Due to the electron deficiency of a benzene ring. the decomposition of phenol. CPs. and $\mathrm{CNB}$ using $\mathrm{OH}$ radical oxidation begins with the strong electrophilic $\mathrm{OH}$ 's attack on the carbon(s) of benzene ring. Thus. it is best to review the electron density of the carbon found in a benzene ring in analy zing the oxidation reaction. In other words, the ligher the value of negative charge of the carbon forming the benzene rings of phenol. CPs. and CNB reach high points, the easier the attack by the electroplilic . $\mathrm{OH}$ is made. Accordingly. in this study. concerning the molecular structure obtained from the BLYP/6-311++G(d.p) optimization. the atomic charge distribution of each carbon atom using CHelpG and MK charges method was calculated and the results are shown in Table 3 .

Looking at the values of CHelpG and MK charge in the Table 3, we found that carbon 6 has the lighest negative electric charge of -0.272 and -0.345 , respectively, followed by carbon 2 with -0.200 and -0.261 and carbon 4 with -0.157 and -0.179 . In the experimental results. the catechol (CT) also generated after the $-\mathrm{OH}$ group was substituted in carbon 6 or carbon 2 and the hydroquinone (HQ) generated after the $-\mathrm{OH}$ group was substituted in the catechol (CT) and carbon 4 are considered as products. ${ }^{32 \cdot 36}$ In most cases, ${ }^{3+-36}$ the produced quantity of CT was higher than that of HQ. This shows the identical tendency that the negative clarges of carbon 6 and

Table 2. Literature summary of ozone and Fenton oxidation of CPs.

4-chloronitrobenzene


Table 3. Comparison of atomic charges of radical reaction products of phenol, monochlorophenols and 4-chloronitrobenzene.

\begin{tabular}{|c|c|c|c|}
\hline \multirow{2}{*}{ Target Substance } & \multirow{2}{*}{ Position } & \multicolumn{2}{|c|}{ Charges } \\
\hline & & $\mathrm{MK}$ & CHelpG \\
\hline \multirow{6}{*}{$\mathrm{O}^{-\mathrm{H}}$} & 1 & 0.472 & 0.407 \\
\hline & 2 & -0.261 & -0.200 \\
\hline & 3 & -0.083 & -0.049 \\
\hline & 4 & -0.179 & -0.157 \\
\hline & 5 & -0.049 & -0.016 \\
\hline & 6 & -0.345 & -0.272 \\
\hline \multirow{6}{*}{$\mathrm{H}$} & 1 & 0.500 & 0.425 \\
\hline & 2 & -0.158 & -0.079 \\
\hline & 3 & -0.022 & -0.040 \\
\hline & 4 & -0.222 & -0.166 \\
\hline & 5 & -0.057 & -0.026 \\
\hline & 6 & -0.321 & -0.261 \\
\hline \multirow{6}{*}{ H } & 1 & 0.440 & 0.411 \\
\hline & 2 & -0.295 & -0.294 \\
\hline & 3 & 0.042 & 0.161 \\
\hline & 4 & -0.101 & -0.134 \\
\hline & 5 & -0.157 & -0.091 \\
\hline & 6 & -0.282 & -0.205 \\
\hline \multirow{6}{*}{ Cl } & 1 & 0.480 & 0.417 \\
\hline & 2 & -0.416 & -0.323 \\
\hline & 3 & 0.028 & 0.018 \\
\hline & 4 & -0.023 & 0.025 \\
\hline & 5 & -0.030 & -0.039 \\
\hline & 6 & $\begin{array}{l}-0.304 \\
\ldots \ldots \ldots \ldots\end{array}$ & $\begin{array}{l}-0.225 \\
\ldots \ldots \ldots \ldots\end{array}$ \\
\hline \multirow{6}{*}{$\int_{0=1}^{C}$} & 1 & -0.034 & 0.065 \\
\hline & 2 & 0.038 & -0.021 \\
\hline & 3 & $-0.27 \hat{3}$ & -0.130 \\
\hline & 4 & 0.206 & 0.067 \\
\hline & 5 & -0.273 & -0.130 \\
\hline & 6 & 0.038 & -0.021 \\
\hline
\end{tabular}

carbon 2 reach higher values than those of carbon 4 as a result of calculating charges

As a result of the calculation of CHelpG and MK, the atomic charge of 2-chlorophenol which chlorine was substituted in the ortho position of phenol. reached lighest values with -0.261 and -0.321 , respectively, at the carbon 6 and followed by -0.166 and -0.222 at the carbon 4 . These results of CHelpG and MK accurately correspond with those of products generated by the substitution of $\mathrm{OH}$ group in carbon 6 and carbon 4 in the previous studies. ${ }^{37.38}$

The CHelpG and MK charges of 4-chlorophenol generated by the substitution of chlorine in the para position of phenol. the carbon 2 reached very high negative values with -0.323 and -0.416 . respectively. and with -0.225 and -0.304 . respectively. at the carbon 6 . Meanwhile. carbon 3 has positive charges with 0.018 and 0.028 and carbon 5 has very small negative charges with -0.039 and -0.030 . As a result. based on the position of $\mathrm{OH}$ of phenol, it seems that carbons 2 and 6 located in the ortho positions are easily attacked by $\cdot \mathrm{OH}$. whereas carbons 3 and 5 in the meta positions rarely caused
$\mathrm{OH}$ to be substituted due to a positive charge or a small negative one. These results showed the correspondence with those of the previous experimental report ${ }^{\text {ty }}$ that only 4-chlorocatechol created by the substitution of $\mathrm{OH}$ is generated at the ortho position and 4-chloro-1.3-dilydrosybenzene is not produced.

The charge of 3-chlorophenol (3-CP) generated by the substitution of cllorine at the meta position reached very ligh values at the carbon 2 with -0.294 and -0.295 . respectively, and at the carbon 6 with -0.205 and -0.282 , respectively. in CHelpG and MK. The carbon 4 reached the second highest negative value with $-0.13+$ in CHelpG but it showed a value of -0.101. which was lower than -0.157 of the carbon 5 in MK. In the experimental report. ${ }^{410}$ the initial product percentage of 3-chlorocatechol generated by the substitution of $\mathrm{OH}$ at the carbon 2 position reached $8 \%$. 4-chlorocatechol generated in the same way at the carbon 6 position reached $15 \%$. and that at the carbon 4 reached $3 \%$. Looking at these results, we found that the CHelpG charge is more appropriate than the MK charge in predicting the $\mathrm{OH}$ substitution by radical oxidation reaction on $3-\mathrm{CP}$.

In case of the CNB, the values of CHelpG and MK charges at the carbons 3 and 5 which are symmetrically located. indicated as -0.130 and -0.273 . respectively. Meanwhile the carbons found in other positions indicated positive charges or negative charges of very small value. In the literature. ${ }^{32}$ it was reported that 5-chloro-2-nitrophenol (5-Cl-2-NP) and 2-chloro5-nitrophenol (2-Cl-5-NP) are all generated. However, considering the results of charge calculation obtained in this study. it was predicted that the products generated by hydroxyl substitution reaction using $\cdot \mathrm{OH}$ reaction will be 5 - $\mathrm{Cl}-2-\mathrm{NP}$ and the amount of produced 2-Cl-5-NP will be small or almost none.

\section{Conclusions}

The following results were obtained by comparing the atomic charge values calculated by using the $\mathrm{CHelpG}$ and $\mathrm{MK}$ methods with optimized structure of BLYP/6-311++G(d.p) with the oxidation products of phenol, three kinds of CPs. and CNB reported in the literatures.

1. Based on the comparison of the experimental results. it has been identified that the $\mathrm{OH}$ group originating from $\cdot \mathrm{OH}$ was substituted at the position of the carbon whose negative charge distribution among the benzene ring of the target compound was highly dense.

2. In the case of 3-CP, the CHelpG charge value was more efficiently used than $\mathrm{MK}$ charge value in predicting radical oxidation products.

3. In the case of $\mathrm{CNB}$, judging from the charge calculation. it is expected that $5-\mathrm{Cl}-2-\mathrm{NP}$ is more advantageous than $2-\mathrm{Cl}-5-\mathrm{NP}$ as $\mathrm{OH}$ substitute product by $\cdot \mathrm{OH}$ reaction.

Aclnowledgments. B.-D. Lee and M.-J. Lee acknowledge this work is financially supported by the Korea Research Foundation Grant funded by the Korean Govenmment (MOEHRD) (KRF-2006-333-D00281) and Changwon National University in 2008. respectively 


\section{References}

1. Jones, P. A. In Chlorophenol and Their Impurities in the Canadian Emiromment, Environment Canladian Econ. Tech. Rev. Report EP S-3-EC-81-2: 2000; p 434.

2. Priorin substances list assessment report: halogenated compoinds: Canadian Environmental Protection Act: 1994; p 74.

3. Kemnes, C.: Wu, W. M.; Bhatnagar, L.: Zeikus, J. G. Appl. Microbiol. Biotechnol. 1996, 4t, 801.

4. Matafonova, G.; Christoti, N.; Batoev, V.: Sosnin, E. Chemosphere 2008, 70, 1124.

5. Jung, O.-T. Bull Korean Chem. Soc. 2001, 22, 1183.

6. Kim, T.-Y.; Moon, S.-H. J. Air \& Waste Manage Assoc. 2000, 50,555

7. Leung, S. W.; Watts, R. T.; Miller, G. C. J. Emiron. Qtral. 1992, 21,377 .

8. Lee, C.: Yang, W.; Part, R. Phss. Rev B 1998, 37, 785

9. Mineva, $T$ : Russo, N. Inter: J. Ounnmm Chem. 1997, 61, 665

10. Fueno, H.; Tanaka, K; Sugawa, S. Chemosphere 2002, +18, 771 .

11. Akai, N.: Kudoh, S: Takayanagi, M.; Nakata, M. J. Photochem. and Photobiol it Chem. 2001, 146,49 .

12. Conner, A. H. J. Appl Polym. Sci. 2000, $78,355$.

13. Mitsunaga, T.; Conner, A. H; Hill, Jr. C. G. J. Appl. Polvm. Sct. $2002,86,135$.

14. Mitsunaga, T:; Comner, A. H.: Hill, Jr. C. G. J. Hood Sci. 2002, 48,153

15. Jung, O.-T. Bull. Korean Chent. Soc, 2001, 22, 850 .

16. Sung, M.: Huang, C. P. Envint. Sci. Techol. 2002, 36, 2911.

17. CS Chem 3D Pro: Cambridgesoft Co: Cambridge, MA, USA, 1999.

18. Frisch, M. J; Trucks, G. W: Schlegel, H. B.; Scuseria, G. E.; Robb, M. A.; Cheeseman, J. R.; Zakizewski, V. G.: Montgomery, J. A: Stratmanu, R. E; Burant, I. C: Dapprich, S.; Millam. J. M.: Daniels, A. D.: Kudin, K. N.: Strain, M. C.: Farkas, 0.: Tomasi, J: Barone, V.: Cossi, M: Canuni, R: Mennucci, B.: Pomelli, C.: Adamo, C.: Cliftord, S.; Ochterski, J.; Petersson, G. A: Ayala, P. Y: Cui, Q.: Morokuma, K: Rega, N.: Salvador, P.: Danuenterg, J. T.: Malick, D. K.; Rabuck, A. D.:
Raghayachari, K.: Foresman, I. B.: Cioslowski, J.: Ortiz, I. V.; Baboul, A. G.: Stefanov, B. B.: Liu, G.: Liashenko, A.: Piskorz, P.; Komaromi, I.; Gomperts, R.; Martin, R. L.: Fox, D. J.: Keith, T:; Al-Laham, M. A.: Peng. C. Y.: Nanayakkara, A.; Challacombe, M.; Gill, P. M.; Johnson, B.; Chen, W.: Wong, M. W:; Andres, J. L.; Gonzalez, C.; Head-Gordon, M.; Replogle, E. S.; Pople, J. A. Ganssian 98: Gaussian Inc: Pittsburgh, PA, 2001

19. Becke, A. D. Phys Rev A 1988, 38, 3098

20. Adomo, C.: Barone, V. Chem. Phys. Lett 1977, 27f, 242

21. Breneman, C. M.; Francl, M. M. J. Contp. Chent. 1990, 11, 361.

22. Besler, B. H.; Merz, Jr., K. M.; Kollman, P. M. J. Conp. Chem. $1990,11,431$.

23. Singh, U. C, Kollman, P. A. J. Comp. Chem 1984, $5,129$.

24. Verkatadri, R.; Peters, R. W. Hazarl Waste \& Hazarl Mater: $1993,10,107$.

25. Walling, $\mathrm{C}$. Acc. Chent Res. 1975, 8, 125.

26. Sung, M.; Huang, C.-P. J. Hazard Mater. 2007, 141, 140.

27. Barbeni, M.: Minero, C.: Pelizzetti, E. Chemosphene 1987, 16. 2225.

28. Du, Y:; Zhou, M.; Lei, L. J. Hazard hater. 2007, B139. 108

29. htp : www-old itcilo.org.

30. Martha, W: Susan, B.: Lorraine, Y. S.: Margaret N. F. In The Merch Index, $10^{\text {th }}$ ed:; Merck \& Co.: Rathway, 1983.

31. Hayek, N. A.; Dore, M. Envinon. Techol Letrers 1985, 6, 37.

32. Shen, J-m.; Chen, Z.-1; Xu, Z.-z; Li, X.-y; Xu, B.-b; Qi, F. J. Hazam. Water, 2008, 152, 1325 .

33. Norefia-Franco, L.; Hemandez-Perez, I.; Aguilar-Pliego, T.; Maubert-Franco, A. Catalysis Todav 2002, 75, 189.

34. Barıal, V. K.; Kumar, R; Prasad, R.; Prasad, S.; Niraj $J$. Whol. Catolvsis A: Chem 2008, 284, 69.

35. Parida, K. M.; Mallick, S. J. Hol. Catalsis A: Chem 2008, 279, 104.

36. Wang, L; Kong, A.; Chen, B.; Ding, H.; Shan, Y; He, M. J. Mol. Catalysis $A$ : Chem 2005, 230,143 .

37. Miller, I. S. Water Res. 2005, 39,412.

38. Bertelli, M.; Selli, E. J. Hazd. Hater: 2006, B138, 46.

39. Waldner, G.: Pourmodjib, M.; Bamer, R.: Neuman-Spallart, M. Chemosphere 2003, $50,989$.

40. Mazellier, P.; Bolte, M. Chemosphere 2001, 42, 361. 